\title{
A REVISION OF THE EARTHWORM GENUS DIGASTER \\ (Megascolecidae, Oligochaeta)
}

\author{
By B. G. M. JAMIEson \\ Department of Zoology, University of Sydney
}

(Figs. I-7)

Manuscript received 20-9-62

\section{SUMMARY}

The account begins with a brief review and discussion of recent trends in the systematics of the Megascolecidae.

The genus Digaster Perrier 1872 is revised and Perissogaster Fletcher 1887 is united with it. The status of the digastric genus Didymogaster Fletcher I 886 is discussed and reasons are given for retaining the genus although Fletcher's definition no longer merits separation from Digaster.

A definition of Digaster s. lat. is followed by a key to all constituent species and a discussion of morphology and affinities in the genus.

Descriptions of six of the eleven species of the extended genus, based on new and/or type-material, are given, together with new information from the types of D. (= Perissogaster) nemoralis.

\section{INTRODUCTION}

This revision of Digaster stems from an identification, as D. longmani, of giant earthworms collected in Northern New South Wales by Miss E. Pope, of the Australian Museum. Before the taxonomic section is commenced, recent trends in the systematics of the Megascolecidae, the largest family of earthworms, and the only group of earthworms native to Australia, will be outlined.

Two recent events of major importance in the taxonomy of the Megascolecidae have been reduction in number of the Megascolecid subfamilies from four to two by Lee (1959), in his monograph of the earthworm fauna of New Zealand, and the elevation of the four subfamilies to family rank by Gates (I959). These conflicting actions reflect a common disenchantment among present-day oligochaetologists with the "Notiodrilus theory" adhered to so closely by Michaelsen (e.g. 1909) and by Stephenson in his great monograph (1930).

Followers of the Notiodrilus theory strove to arrange all Megascolecidae in a family tree springing from an Acanthodriline stem genus with the morphology of the extant Notiodrilus. To do this, generic definitions were limited to relatively few characters, mainly setae, location of male and prostatic openings and of spermathecal pores, number of gizzards, form of prostates and andry. The shortcomings of this system have been demonstrated by Gates (1959, I958, 1942, etc.), who campaigned for more emphasis on somatic characters such as the blood vascular system, calciferous glands and other features of the alimentary canal, and also by Lee (1959), who gave a useful review of Michaelsen's classical work leading to the delimitation of the Megascolecid subfamilies, and by Jamieson (1963). The latter paper, and that of 